\title{
Note
}

\section{Translocation of Barley $\beta$-amylase into Rice Grains during Cooking Rice Mixed with Barley (Mugimeshi)}

\author{
Anna SAno ${ }^{1}$, Mika Tsuyukubo ${ }^{1 \$}$, Yuka Mabashi ${ }^{1}$, Yukie MurakamI ${ }^{2}$, Hiroshi Narita ${ }^{3}$, Midori Kasai and \\ Tetsuya OOKURA ${ }^{4 *}$ \\ ${ }^{1}$ Department of Nutrition and Food Science, Graduate School of Humanities and Sciences, Ochanomizu University, 2-1-1 \\ Otsuka, Bunkyo-ku, Tokyo 112-8610, Japan \\ ${ }^{2}$ Kyoto College of Nutritional \& Medical Sciences, Setogawa-cho 18, Saga Tenryuji, Ukyo-ku, Kyoto 616-8376, Japan \\ ${ }^{3}$ Department of Food and Nutrition, Kyoto Women's University, Kitahiyoshi-cho 35, Imakumano, Higashiyama-ku, Kyoto \\ 605-8501, Japan \\ ${ }^{4}$ Food Function Division, Food Research Institute, National Agriculture and Food Research Organization, 2-1-12 Kan- \\ nondai, Tsukuba, Ibaraki 305-8642, Japan
}

Received March 6, 2017 ; Accepted April 19, 2017

Cooking rice mixed with barley, called Mugimeshi in Japanese, is one of the most common multi-grain cooking styles in Japan. While the localization and functions of rice starch-degrading enzymes such as $\alpha$ - and $\beta$-amylases during rice cooking have been well studied, those of barley enzymes remain unknown - especially when barley is cooked with rice. In this study, we investigated the localization of barley $\beta$-amylase using an immunoblot technique when barley and rice were soaked in water and heated together to $60^{\circ} \mathrm{C}$. Surprisingly, barley $\beta$-amylase was found not only in barley grains and cooking water, but also in rice grains after barley and rice were soaked in water for one hour. In rice grains, the amount of barley $\beta$-amylase was highest when the water temperature reached $40^{\circ} \mathrm{C}$. These data clearly showed that some barley $\beta$-amylase was translocated from barley grains into rice grains through the cooking water. The finding raises the possibility that in addition to rice enzymes, barley $\beta$-amylase contributes to rice starch degradation during Mugimeshi cooking.

Keywords: barley, $\beta$-amylase, immunoblot, Mugimeshi, lipid transfer protein

\section{Introduction}

Barley (Hordeum vulgare) is one of the major human food crops along with maize, rice and wheat. The worldwide barley production was 144 million tons in 2014 for food, livestock feed, and alcoholic beverages.
In Japan, Korea, Nepal, and Ethiopia, barely has been traditionally consumed with rice (as Mugimeshi in Japan), with vegetables (as Bori in Korea), as barley tea, or as thin-baked bread (as Tsampa in Tibet and Injera in Ethiopia). Even though barley provides more nutrients such as vitamins, minerals, and dietary

\section{Abbreviations \\ SDS-PAGE, sodium dodecyl sulfate polyacrylamide gel electrophoresis}

${ }^{\text {\$ }}$ Present address; Department of Nutritional Sciences, Faculty of Food and Nutritional Sciences, 1-1-1, Izumino, Itakura-machi, Ora-gun, Gunma 374-0193, Japan

*To whom correspondence should be addressed. 
fiber than polished rice (Roth-Maier et al., 1999, Roth-Maier et al., 2002), barley consumption in Japan has been decreasing during the last fifty years, presumably due to its non-sticky texture and cardboard-like flavor in Mugimeshi (Hambraeus and Nyberg, 2005, Kuroda et al., 2005, Kaneko et al., 2013). Development of barley cultivars with enhanced taste as well as novel effective cooking methods are thus highly desired.

Compared with other crops, barley contains a large amount of water soluble dietary fiber (1-3), (1-4)- $\beta$-D-glucan ( $\beta$-glucan) (Henry, 1987). A number of beneficial impacts of $\beta$-glucan have been reported such as lowering of cholesterol level (Ikegami et al., 1996), serum glucose level (Granfeldt et al., 1994), and fat accumulation (Shimizu et al., 2008), and normalization of insulin level (Hinata et al., 2007). Recently, a new barley cultivar called Motchiriboshi was developed by Sapporo Breweries Ltd. as a high $\beta$-glucan cultivar. In addition, its low amylose content imparts a glutinous texture to the cooked barley. Based on these beneficial characteristics, Motchiriboshi is suggested to be a suitable cultivar for Mugimeshi cooking.

The physiological characteristics of barley grains and their impact on the texture of cooked barley (pearled, polished, and pressed) were studied by Takahashi and Nakazawa with the following observations: (1) 2.2 times the amount of water to barely (by weight basis) was required for barley cooking (Takahashi and Nakazawa, 1981), (2) the amount of void fraction of barley grains differed among barley cultivars (Takahashi and Nakazawa, 1983), and (3) the rheological parameters of cooked barley such as viscosity and elasticity were primarily correlated with stickiness and firmness, as measured by sensory evaluation (Takahashi and Nakazawa, 1982). However, with respect to Mugimeshi, these physiological data as well as the optimal cooking conditions have not yet been reported.

To understand how crop starch is hydrolyzed during cooking, we focused on $\beta$-amylase as the starch-degrading enzyme. Using immunoblot analysis with an antibody against rice $\beta$-amylase, we showed that $\beta$-amylase was hardly detected in whole rice grains of the rice cultivar Nipponbare (Tsuyukubo et al., 2013). However, the distribution and functions of barley $\beta$-amylase during cooking have not been reported especially when barley is cooked with rice (Mugimeshi). We therefore analyzed the localization of barley $\beta$-amylase in barley grains, rice grains, and cooking water during Mugimeshi cooking using an antibody against barley $\beta$-amylase.

\section{Materials and Methods}

Materials Reagents and chemicals were purchased from the following commercial sources: protein markers from New England Biolabs (Tokyo, Japan), bis-acrylamide from Sigma (St. Louis, MO), horseradish peroxidase-labeled anti-mouse IgG antibody from Cappel (Costa Mesa, CA), protein assay kit and nitrocellulose membranes from Bio-Rad (Richmond, CA), acrylamide, horseradish peroxidase-labeled anti-rabbit IgG antibody, epoxy activated Sepharose, and chemi-luminescent reagent from GE Healthcare (Buckinghamshire, UK). Other reagents were purchased from Wako Pure Chemicals (Osaka, Japan) unless otherwise noted.

Barley and rice samples Barley (Hordeum vulgare L. cv. Motchiriboshi) grains grown in Saitama in 2013 were pearled and polished to $75 \%$ by Nagakura Seibaku K. K. (Shizuoka, Japan) and stored at $4{ }^{\circ} \mathrm{C}$ until use. Brown rice (Oryza sativa L. cv. Nipponbare) grown in Shiga in 2012 was milled to $90 \%$ with an MC90A (Toyo Rice Cleaning Machine, Osaka, Japan) just before each experiment.

Preparation of crude enzyme extracts from barley grains, rice grains, and cooking water during barley rice cooking Equal dry weights of barley grains (Motchiriboshi) and rice grains (Nipponbare) were used. Crude enzymes were prepared based on the method previously described (Tsuyukubo et al., 2012). Barley grains and rice grains were soaked in distilled water (ratios of 1 barley: 1.8 water and 1 rice: 1.5 water) for $1 \mathrm{~h}$ at $20^{\circ} \mathrm{C}$. The barley/ rice mixed grains or rice grains were heated using the electric rice cooker SR-03F (Panasonic, Osaka, Japan) controlled by a volt slider (V-130-5; Yamabishi, Tokyo, Japan). The temperature was regulated to boil the grains after $11 \mathrm{~min}$ in order to achieve a similar condition to practical rice cooking procedures. Barley grains, rice grains, and cooking water were separated at the following three different time points: after soaking $\left(20^{\circ} \mathrm{C}\right)$, when the temperature reached $40^{\circ} \mathrm{C}$, and when the temperature reached $60^{\circ} \mathrm{C}$. All collected samples were freeze-dried. The freeze-dried rice and barley grains ( $2 \mathrm{~g}$ as raw grains) were ground and suspended in $20 \mathrm{~mL}$ of PBSD medium containing $50 \mathrm{mM}$ sodium phosphate buffer (pH 7.0), $5 \mathrm{mM}$ dithiothreitol (DTT), $100 \mathrm{mM}$ $\mathrm{NaCl}$ and $0.1 \%$ sodium dodecyl sulfate (SDS). The freeze-dried cooking water samples were suspended in $10 \mathrm{~mL}$ of the same buffer. Proteins were extracted by shaking the suspended mixtures at $20^{\circ} \mathrm{C}$ for $1 \mathrm{~h}$. The mixtures were centrifuged at 3,000 rpm for $20 \mathrm{~min}$ at $4^{\circ} \mathrm{C}$. After filtration, the supernatants were used as crude enzyme extracts.

Protein assay Total protein in crude extracts was determined using a Bio-Rad protein assay kit with bovine serum albumin solution as the standard (Bradford, 1976).

Affinity purification of barley $\beta$-amylase $\alpha$-Cyclodextrin was immobilized to epoxy activated Sepharose 6B (GE Healthcare) as described previously (Totsuka and Fukazawa, 1993). The crude enzyme extract prepared from barley grains (GBA2; Godo Shusei Co. Ltd, Tokyo, Japan) in $50 \mathrm{mM}$ sodium acetate ( $\mathrm{pH} 5.7$ ) containing $1.5 \mathrm{M}\left(\mathrm{NH}_{4}\right)_{2} \mathrm{SO}_{4}$ was applied to the $\alpha$-cyclodextrin immobilized Sepharose 6B column. After extensive washing with the same buffer, $\beta$-amylase was eluted with $50 \mathrm{mM}$ sodium acetate (pH 5.7) containing $0.8 \mathrm{M}\left(\mathrm{NH}_{4}\right)_{2} \mathrm{SO}_{4}$.

Preparation of polyclonal antibody against barley $\beta$-amylase Antibodies against barley $\beta$-amylase were raised in rabbits injected with the affinity purified barley $\beta$-amylase.

The antibodies were then pre-absorbed against rice 


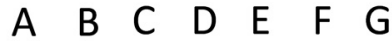

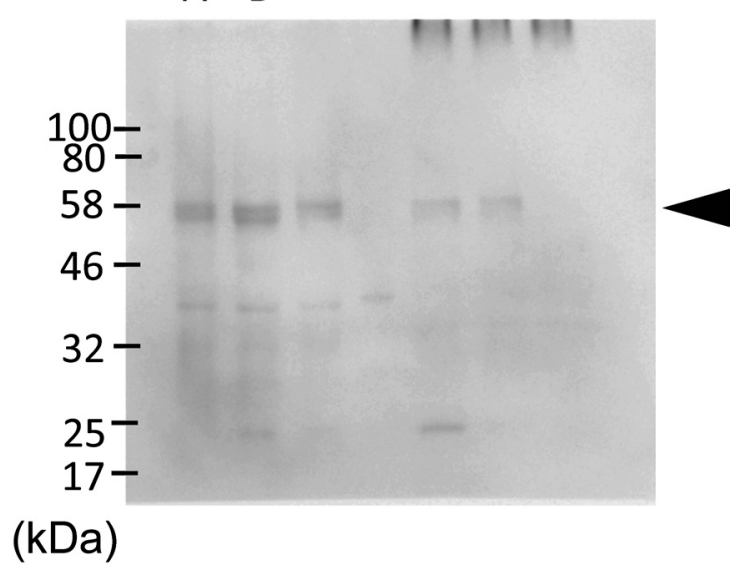

Fig. 1. Immunoblot showing the elution of barley $\beta$-amylase from grains into cooking water during barley cooking

After barley grains were soaked in water at $20^{\circ} \mathrm{C}$ for an hour, the water temperature was raised to $60^{\circ} \mathrm{C}$ as described in Materials and Methods.

Raw barley grains ( $2 \mathrm{mg}$ of raw barley) were extracted without a soaking step and applied to the lane A. Barley grains extract (2 mg of raw barley per lane; B-D) and cooking water $(0.2 \%(\mathrm{v} / \mathrm{v})$ of total cooking water per lane; E-G) were prepared at the end of soaking step (lane $\mathrm{B}$ and $\mathrm{E}$ ), at the temperature reached $40^{\circ} \mathrm{C}$ (lane $\mathrm{C}$ and $\mathrm{F}$ ), and at the temperature reached $60^{\circ} \mathrm{C}$ (lane D and G). Samples were analyzed by immunoblot probed with the polyclonal rabbit antibarley $\beta$-amylase and anti-rabbit IgG conjugated with horseradish peroxidase. Molecular sizes are indicated on the left. The molecular weight of $\beta$-amylase of barley was $55 \mathrm{kDa}$ (solid arrowhead).

(Nipponbare) powder to prevent non-specific binding.

Production of monoclonal antibody against barley lipid transfer protein 1 (LTP1) Production of monoclonal antibody against barley LTP1 was carried out according to the previous report (Murakami-Yamaguchi et al., 2012).

SDS polyacrylamide gel electrophoresis (SDS-PAGE) Crude enzyme extracts from barley grains, rice grains, and cooking water were prepared as described above. The following samples were loaded onto SDS-PAGE gels: barley grains extract (1 mg per lane), rice grains extract (10 $\mathrm{mg}$ per lane), and cooking water samples $(1 / 1000$ of total volume per lane). Samples were separated using $10 \%$ ( $\beta$-amylase) or $15 \%$ (LTP1) acrylamide gels (Laemmli, 1970) and stained with $0.2 \%(\mathrm{w} / \mathrm{v})$ Coomassie Brilliant Blue R-250 in $40 \%(\mathrm{v} / \mathrm{v})$ methanol and $10 \%(\mathrm{v} / \mathrm{v})$ acetic acid.

Immunoblotting After SDS-PAGE, proteins were transferred to nitrocellulose membranes (Bio-Rad) using a transfer system (Nihon Eido, Tokyo, Japan) as described previously (Towbin et al., 1979, Tsuyukubo et al., 2010). The membrane was blocked with StartingBlock (PBS) blocking solution (Thermo Scientific, Yokohama, Japan) containing 10\% normal horse serum (Kojin Bio, Saitama, Japan) and probed with polyclonal anti-barley $\beta$-amylase (88-1; 1: 2,000 dilution) and anti-rabbit IgG antibodies (GE Healthcare; 1: 2,000 dilution) conjugated with horseradish peroxidase in the case of $\beta$-amylase. For LTP1, the membrane was
A $\quad B \quad C \quad D \quad E \quad F \quad G$

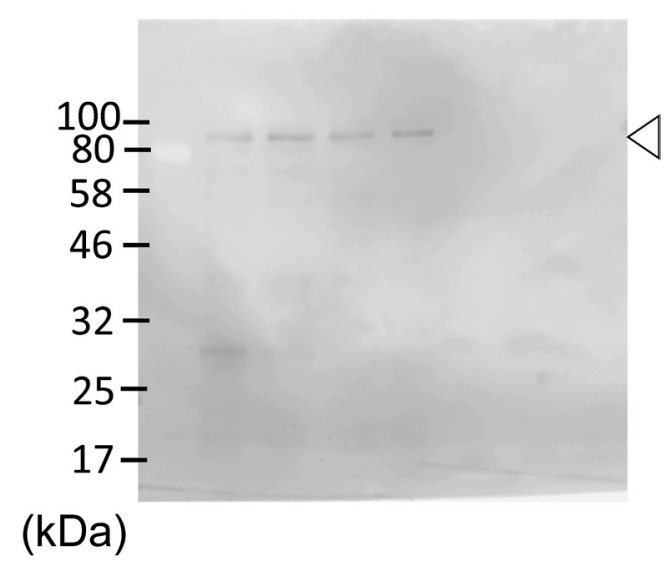

Fig. 2. No cross-reactivity of the anti-barley $\beta$-amylase antibody against a $55 \mathrm{kDa}$ protein in rice (Nipponbare).

Raw rice grains ( $10 \mathrm{mg}$ of raw rice) were extracted without a soaking step and applied to the lane A. Rice grains were heated with the same condition as described in Materials and Methods. Rice grains extract $(10 \mathrm{mg}$ of raw rice per lane; lane B-D) and cooking water $(0.2 \%(\mathrm{v} / \mathrm{v})$ of total cooking water per lane; lane E-G) were prepared at the end of soaking (lane $\mathrm{B}$ and $\mathrm{E}$ ), after the temperature reached $40^{\circ} \mathrm{C}$ (lane $\mathrm{C}$ and F), and after the temperature reached $60^{\circ} \mathrm{C}$ (lane D and G). Samples were probed with the same antibody in Figure 1. Open arrowhead indicates unknown $80 \mathrm{kDa}$ proteins in rice grains.

probed with monoclonal anti-barley LTP1 antibody (10-4; $1.0 \mu \mathrm{g} /$ $\mathrm{mL}$ ) and anti-mouse $\operatorname{IgG}$ antibody conjugated with horseradish peroxidase (Cappel; 1: 5,000 dilution).

Immuno-reactive bands were analyzed using an LAS-4000 molecular imager (Fujifilm, Tokyo, Japan) after the membrane was developed with a chemi-luminescent reagent (GE Healthcare).

\section{Results and Discussion}

Elution of barely $\beta$-amylase to cooking water during barley cooking To analyze the localization of barley $\beta$-amylase during barley cooking, barley grains and cooking water were collected at three time points of the cooking process - after soaking in water, when the temperature reached $40^{\circ} \mathrm{C}$, and when the temperature reached $60^{\circ} \mathrm{C}$ - and immunoblot analysis using anti-barley $\beta$-amylase polyclonal antibody (88-1) was carried out as described in the Materials and Methods. Barley $\beta$-amylase was also extracted from barley grains without the soaking step. Barley $\beta$-amylase was detected in the barley grains extract at the expected size $(55 \mathrm{kDa})$ (Figure 1, lane A; solid arrowhead). During the cooking process, barley $\beta$-amylase was detected in the barley grains extract and cooking water, and the amount of $\beta$-amylase was gradually decreased through the heating process (Fig. 1, lanes B-D; lanes E-G).

Cross-reactivity of anti-barley $\beta$-amylase antibody against rice proteins To check the possibility that the anti-barley $\beta$-amylase antibody (88-1) cross-reacted with rice $\beta$-amylase or other rice proteins, immunoblot analysis of the rice grains extract and 
Panel 1

A $\quad$ B $C$ C

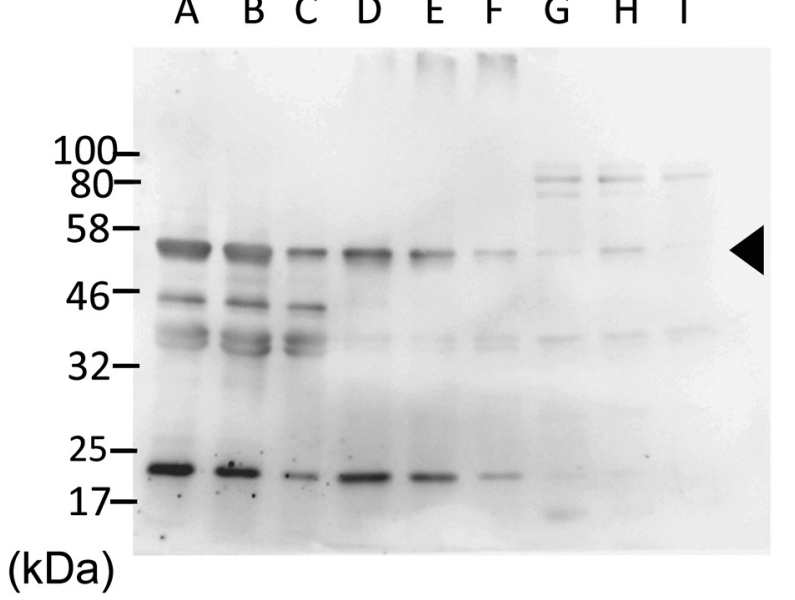

\section{Panel 2}

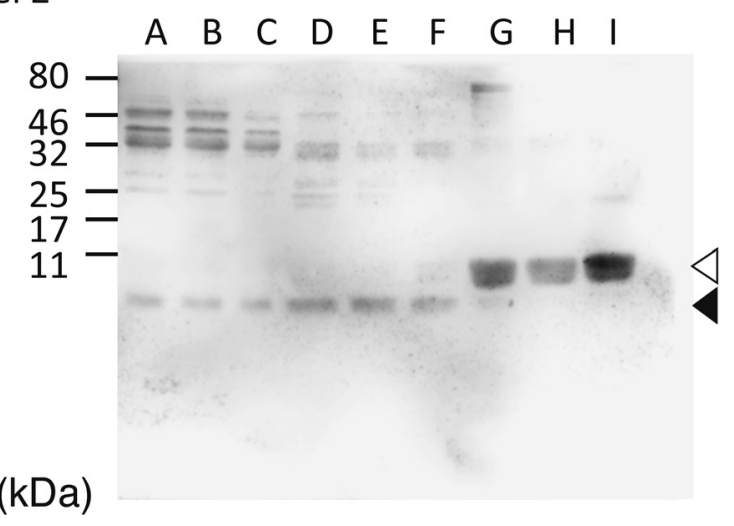

Fig. 3. Immunoblot showing the localization of $\beta$-amylase and LTP1 in barley grains, rice grains, and cooking water during cooking rice mixed with barley (Mugimeshi cooking).

Panel. 1. The same amount of barley and rice grains were mixed and soaked in cooking water (barley 1:1.8 water and rice 1:1.5 water) at $20^{\circ} \mathrm{C}$ for an hour and then cooked up to $60^{\circ} \mathrm{C}$. The barley grains extract (lane A-C), rice grains extract (lane G-I) and cooking water extract (lane D-F) were prepared at the end of soaking (lane A, D, and G), after the temperature reached $40^{\circ} \mathrm{C}$ (lane $\mathrm{B}, \mathrm{E}$, and $\mathrm{H}$ ), and after the temperature reached $60^{\circ} \mathrm{C}$ (lane $\mathrm{C}, \mathrm{F}$ and $\mathrm{I}$ ). Each lane for barley and rice grains extract contained the amount equivalent to $2 \mathrm{mg}$ of raw barley and to $10 \mathrm{mg}$ of raw rice. Each lane for the cooking water extract contained the amount equivalent to $0.2 \%(\mathrm{v} / \mathrm{v})$ of total cooking water. The molecular weight of $\beta$-amylase of barley was $55 \mathrm{kDa}$ (solid arrowhead). Antibodies used were same as Figure 1.

cooking water using the same antibody was conducted on only rice grains heated at the same conditions. The polyclonal antibody against barley $\beta$-amylase did not react with a $55 \mathrm{kDa}$ protein, which corresponds to the size of $\beta$-amylase, in both rice grains and cooking water at any of the cooking time points (Figure 2, lanes A-D; lanes E-G). These data indicated that the polyclonal antibody did not react with the intrinsic rice $\beta$-amylase, but reacted with an unknown $80 \mathrm{kDa}$ (open arrowhead) protein in the rice grains extract. This observation was consistent with our previous report, which showed that $\beta$-amylase in Nipponbare was hardly detected, throughout the rice grains, with anti-rice $\beta$-amylase monoclonal antibody (Tsuyukubo et al., 2013).

Localization of barely $\beta$-amylase during cooking of rice mixed with barley (Mugimeshi cooking) To analyze the localization of barley $\beta$-amylase when barley and rice were cooked together, barley grains, rice grains, and cooking water were collected at three time points of the cooking process as described above. Barley $\beta$-amylase was detected in the barley grains extract and cooking water at $55 \mathrm{kDa}$, and the amount of $\beta$-amylase was gradually decreased during the heating process (Fig. 3-1, lanes A-C; lanes $\mathrm{D}-\mathrm{F}$; solid arrowhead). The results showed that the majority of barley $\beta$-amylase was released from barley grains to the cooking water during cooking. Surprisingly, barley $\beta$-amylase was weakly
Panel. 2. Control immunoblot experiments were carried out with the antibody against barley LTP1. Samples for each lane were same as Panel 1. Samples were probed with the mouse monoclonal antibody against barley LTP1 and anti-mouse IgG conjugated with horseradish peroxidase. The molecular weight of barley LTP1 was $9 \mathrm{kDa}$ (solid arrowhead). Open arrowhead indicates rice LTP1.

detected in the rice grains extract after the soaking step and when the cooking water temperature reached $40^{\circ} \mathrm{C}$ (Fig. 3-1, lanes G-I). After the cooking water reached $60^{\circ} \mathrm{C}$, barley $\beta$-amylase was no longer detected in the rice grains extract (Fig. 3-1, lane I). The gradual decrease of barley $\beta$-amylase in barley grains, rice grains and cooking water could be explained by its partial degradation.

Immunoblot analyses demonstrated that barley $\beta$-amylase was detected in the rice grains extract in addition to the barley grains extract and cooking water at the end of soaking and in the early stage of heating (Fig. 3-1). The band intensity observed in the grains extract was most intense at the $40^{\circ} \mathrm{C}$ water temperature time point. From these data, we propose that barley $\beta$-amylase was released from barley grains to the cooking water during the soaking step and subsequently reached the surface of the rice grains. Then, the barley $\beta$-amylase in rice grains was released and/or degraded through the heating process. Ikeda et al. reported that saccharides were highly eluted from rice grains into the cooking water between $40^{\circ} \mathrm{C}$ and $70^{\circ} \mathrm{C}$ during rice cooking (Ikeda, 2001). The barley $\beta$-amylase is likely detached and eluted from rice grains along with the rise in temperature as the saccharides are eluted from the grains.

Localization of LTP1 during cooking of rice mixed with barley (Mugimeshi cooking) LTP1, a $9 \mathrm{kDa}$ basic protein in barley, has been shown to be resistant to enzyme digestion and heat denaturation (Murakami-Yamaguchi et al., 2012). Regarding its resistant character and abundance, we conducted immunoblot analysis of LTP1 during Mugimeshi cooking as a positive control. Analysis of LTP1 behavior during Mugimeshi cooking revealed 
that barley LTP1 was clearly detected in barley grains and cooking water at the expected size (9 kDa) (Fig. 3-2, lanes A-F; solid arrowhead). The monoclonal antibody against barley LTP1 was cross-reactive with rice LTP1 at a high concentration $(1 \mu \mathrm{g} / \mathrm{mL})$. From rice grains, LTP1 was not eluted into the cooking water during soaking or the subsequent heating process (Fig. 3-2, lanes G-I; open arrowhead). Lang reported that variation in the migration speed of LTP1 was observed among rice, millet, rye, and barley (Lang et al., 2011). Differences in migration speed between barley and rice LTP1 is consistent with Lang's report, which used a rabbit polyclonal antibody against recombinant rice LTP1 (Lang et al., 2011). Elution behavior of LTP1 during the cooking process differed between rice and barley. Future studies are required to determine the mechanism of the behavior differences between rice and barley grains.

To our knowledge, this is the first study of the distribution of barley $\beta$-amylase in rice grains during the cooking process of rice mixed with barley (Mugimeshi). The study's findings raise the possibility that barley $\beta$-amylase contributes to rice starch degradation and increases in the sugar contents of the resulting cooked grains.

Acknowledgments We would like to thank to Mr. Takeshi Ebihara for assistance with the immunoblot analysis. This study was partly supported by Kakenhi (23400935) to MT and Kakenhi (23500925) to $\mathrm{MK}$.

\section{References}

Bradford, M. M. (1976). A rapid and sensitive method for the quantitation of microgram quantities of protein utilizing the principle of protein-dye binding. Anal. Biochem., 72, 248-254.

Hambraeus, G. and Nyberg, N. (2005). Enzymatic hydrogenation of trans2-nonenal in barley. J. Agric. Food. Chem., 53, 8714-8721.

Henry, R. J. (1987). Pentosan and $(1 \rightarrow 3),(1 \rightarrow 4)-\beta$-Glucan concentrations in endosperm and whole grain of wheat, barley, oats and rye. Journal of Cereal Science, 6, 253-258.

Hinata, M., Ono, M., Midorikawa, S., and Nakanishi, K. (2007). Metabolic improvement of male prisoners with type 2 diabetes in Fukushima Prison, Japan. Diabetes Res. Clin. Pract., 77, 327-332.

Ikeda, H. (2001). Relationship between the saccharides extracted from rice grains during cooking and the sensory taste of cooked rice. J. Home Econo. Jpn., 52, 401-409 (in Japanese).

Ikegami, S., Tomita, M., Honda, S., Yamaguchi, M., Mizukawa, R., Suzuki, Y., Ishii, K., Ohsawa, S., Kiyooka, N., Higuchi, M., and Kobayashi, S. (1996). Effect of boiled barley-rice-feeding in hypercholesterolemic and normolipemic subjects. Plant Foods Hum. Nutr., 49, 317-328.

Kaneko, S., Kodama, T., Kohyama, N., Watanabe, H., and Hayase, F. (2013). Aroma components characterizing the odor of cooked barley.
Nihon Shokko Gakkaishi, 60, 439-442 (in Japanese).

Kuroda, H., Kojima, H., Kaneda, H., and Takashio, M. (2005). Characterization of 9-fatty acid hydroperoxide lyase-like activity in germinating barley seeds that transforms 9(S)-hydroperoxy-10(E),12(Z)octadecadienoic acid into 2(E)-nonenal. Biosci. Biotechnol. Biochem., 69, 1661-1668.

Laemmli, U. K. (1970). Cleavage of structural proteins during the assembly of the head of bacteriophage T4. Nature, 227, 680-685.

Lang, F.-H., Kagiya, Y., Ohnishi-Kameyama, M., Kawamato, S., Moriyama, T., and Kitta, K. (2011). Immunoblotting analysis of nsLTP1 in cereal grains with antiserum raised against recombinant rice nsLTP1. Food Sci. Tech. Res., 17 499-504.

Murakami-Yamaguchi, Y., Hirose, J., Kizu, K., Okazaki, F., Fujii, W., and Narita, H. (2012). Quality control system for beer developed with monoclonal antibodies specific to barley lipid transfer protein. Antibodies, 1, 259.

Roth-Maier, D. A., Kettler, S. I., and Kirchgessner, M. (2002). Availability of vitamin B6 from different food sources. Int. J. Food Sci. Nutr., 53, 171-179.

Roth-Maier, D. A., Wild, S. I., Erhardt, W., Henke, J., and Kirchgessner, M. (1999). Investigations on the intestinal availability of native thiamin in selected foods and feedstuffs. Eur. J. Nutr., 38, 241-246.

Shimizu, C., Kihara, M., Aoe, S., Araki, S., Ito, K., Hayashi, K., Watari, J., Sakata, Y., and Ikegami, S. (2008). Effect of high $\beta$-glucan barley on serum cholesterol concentrations and visceral fat area in Japanese men a randomized, double-blinded, placebo-controlled trial. Plant Foods Hum. Nutr., 63, 21-25.

Takahashi, J. and Nakazawa, F. (1981). Cooked rice with barley (part1) Cooking conditions. Kaseigakuzasshi., 32, 172-177 (in Japanese).

Takahashi, J. and Nakazawa, F. (1982). Coooked rice with barley (part3) Mechanical Properties of Cooked Rice with Barley. Kaseigakuzasshi, 33, 413-418 (in Japanese).

Takahashi, J. and Nakazawa, F. (1983). Coooked rice with barley (part4) Sensory assensment of the cooked rice with barley and its relation to the rheological parameters. Kaseigakuzasshi., 34, 323-328 (in Japanese).

Totsuka, A. and Fukazawa, C. (1993). Affinity Purification of $\beta$-Amylases originating from plant using cyclomaltohexaose-immobilized Sepharose 6B in the presence of ammonium Sulfate. Protein Expr. Purif., 4, 333336.

Towbin, H., Staehelin, T., and Gordon, J. (1979). Electrophoretic transfer of proteins from polyacrylamide gels to nitrocellulose sheets: procedure and some applications. Proc Natl Acad Sci U. S. A., 76, 4350-4354.

Tsuyukubo, M., Ookura, T., and Kasai, M. (2013). Distribution of starchdegrading enzymes in rice grains of different cultivars and elution behavior during cooking. Food Sci. Technol. Res., 19, 303-311.

Tsuyukubo, M., Ookura, T., Mabashi, Y., and Kasai, M. (2010). Different Distributions of $\alpha$-glucosidases and amylases in milling fractions of rice grains. Food Sci. Technol. Res., 16, 523-530. 
